\title{
Brief Paper: \\ A Design of the Platform Technology for the Smart Shopping Mall Using NFC: A Software Engineering Approach
}

\author{
Seung-Mo Je ${ }^{1}$, Kyungryong $\mathrm{Seo}^{2 *}$
}

\begin{abstract}
An IoT-based server system for store management was developed in this study. Its client-server structure having a product categorization function allows the system to read the NFC tags attached to individual products and provides information about them to customers automatically. The system also provides an effective promotional effect as it not only offers necessary information about the items the customers are seeking but also displays the advertisements related to them. This server system was designed specifically designed for the use in a smart shopping Mall or a department store so that the store owners can manage their sales operation more effectively while their customers enjoy shopping more conveniently. It is expected that the technology used for this IoT-utilized server system can be one of the efficient and effective platform technologies in the current and future store management systems.
\end{abstract}

Key Words: Shopping, Smart Shopping Mall, NFC, Software Engineering, IoT.

\section{INTRODUCTION}

While the quality of life rises in this modern world, shopping behavior holds a special place in people's lives as a very natural and important act. Before proceeding to the main research, we have conducted a survey through SNS asking the shopping mall customers about what are the inconveniences they feel at the shopping malls. The object of such this survey was to provide a better service to the future customers [1].

After analyzing in Fig. 1, we have found that the two most inconvenient experiences were "crowded sales floors" and "uncomfortable burdensome services by the sales clerks". Based on such a result, our team attempted to find a solution onto which a suitable IT technology can be grafted. Thus, we have designed a server which is based on the server-client structure and offers the NFC tag-based item classification function. Our design will generate more promotional effects by showing the customers product advertisements and information selectively as it can identify the needs of customers through the NFC tags. Our ultimate goal is to construct an exclusive IoT server for the huge space in a shopping mall where customers and products interact each other.

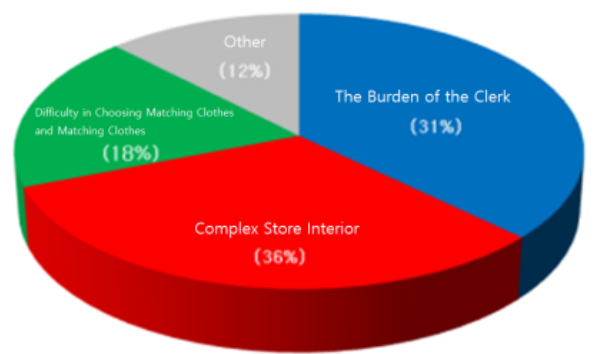

Fig. 1. The Inconveniences Customers Experience at the Shopping Malls.

After analyzing [Fig. 1], we have found that the two most inconvenient experiences were "crowded sales floors" and "uncomfortable burdensome services by the sales clerks". Based on such a result, our team attempted to find a solution onto which a suitable IT technology can be grafted. Thus, we have designed a server which is based on the serverclient structure and offers the NFC tag-based item classification function. Our design will generate more promotional effects by showing the customers product advertisements and information selectively as it can identify the needs of customers through the NFC tags. Our ultimate goal is to construct an exclusive IoT server for the huge space in a shopping mall where customers and products interact each other.

\section{RELATED RESEARCH}

The NFC function can be regarded as one of the domains in the RFID technologies. Its main difference with existing RFID technology is that the NFC technology allows bi-

Manuscript received March 23, 2019; Revised March 27, 2019; Accepted March 28, 2019. (ID No. JMIS-19M-03-010)

Corresponding Author $\left(^{*}\right)$ : Kyungryong Seo, Dept of Computer Engineering, Pukyong National University, Busan, Republic of Korea, krseo@pknu.ac.kr

${ }^{2}$ Dept of Computer Engineering, Pukyong National University, Busan, Republic of Korea, krseo@pknu.ac.kr

${ }^{1}$ Dept. of Computer Science Education, Korea University, Seoul, Republic of Korea, jsm3316@korea.ac.kr 
directional communications. For the RFID communication, one side has to have a reader that can read information provided on the tag hold by the other side and interpret them. On the other hand, the NFC technology provides both functions so that it can offer more services. The common bandwidth used for the NFC technology is $13.56 \mathrm{MHz}$ and its transfer rate is $42 \mathrm{Kbps}$.

Meanwhile, Cloth simulations are usually performed to assess the effect of geometrical variation or physical aspects. In most cases, the former draws faster results without considering the physical properties of the cloth being used. This makes it difficult to reproduce the dynamics of the clothes [1]-[3]. The latter allows more realistic simulation in understanding the dynamics and provides better accuracy as the cloth material's structural properties will be considered for the simulation. In other words, both the law of dynamics and the law of mechanics are based on discrete dynamics, fluid dynamics, or elasticity theories, all of which determine the cloth behavior and its interaction with external environments [4]-[5]. Various methods often categorized as either a continuous physics-based or a discrete physics-based approach have been studied and proposed till now, emphasizing realism or computational efficiency [6]. The former introduces a rigorous, strict representation of a cloth in accordance with the continuum mechanics often adopting either a finite element (FE) or a finite difference model to produce a solution [7-9]. Meanwhile, by using the continuous Lagrange equations to represent the displacements from equilibrium positions, Terozopoulos et al. [7] modeled a surface deformation of a cloth, whereas Eischen et al. [10] employed the nonlinear shell theory and Li and Volkov [11] depicted the image of a cloth immersed in a quasistationary viscous fluid in terms of fluid dynamics. For this, a nonlinear FE method was applied to derive the system equations. This method aimed to produce various types of physical models for computer animation, which are effective in generating the behaviors instead of modeling a certain deformable cloth with high degree of accuracy. This method allowed the qualitative reproduction of similar behaviors without requiring a large number of computations [12]-[13].

A wireless identification system, NFC, allows a reader to identify the contents within a smart card or a tag and is installed in most of the currently available smartphones. Also, the NFC has become one of the core technologies for wireless communication-based transactions and it is expected that it will be used more widely in the future communication-based systems or infrastructures than any other short-distance communication technologies currently available, including Bluetooth or Zigbee [14]-[17].

Also, the technical reviews for the introduction of an RFID system are being actively conducted and the requirements for the system are becoming more diverse. Thus, a method which is able to enhance the RFID technology has been developed along with an efficient technical means of integrating various types of systems [18]-[20]. Meanwhile, a wide range of research on a tag identification algorithm or a multi-reader operating technics in a dense reader environment is being conducted to improve the identification performance of the passive readers as well.

Table 1. Application services of NFC.

\begin{tabular}{|c|c|c|}
\hline \multicolumn{2}{|c|}{ Classification } & \multirow{3}{*}{\begin{tabular}{l}
\multicolumn{2}{c}{ Service Type } \\
Settle bills \\
$\begin{array}{l}\text { Fund transfer through } \\
\text { online account }\end{array}$
\end{tabular}} \\
\hline \multirow{4}{*}{$\begin{array}{l}\text { Application } \\
\text { service based } \\
\text { on the contact } \\
\text { between } \\
\text { mobile } \\
\text { terminals }\end{array}$} & Payment & \\
\hline & Fund transfer & \\
\hline & $\begin{array}{l}\text { Name card } \\
\text { exchange }\end{array}$ & $\begin{array}{l}\text { Exchange of contact } \\
\text { information such as E- } \\
\text { mail, Phone No., and } \\
\text { others. }\end{array}$ \\
\hline & Pairing & $\begin{array}{ll}\text { Wireless access } & \text { for data } \\
\text { exchange } & \text { between } \\
\text { terminals } & \end{array}$ \\
\hline \multirow{3}{*}{$\begin{array}{l}\text { Personal } \\
\text { information } \\
\text { management } \\
\text { application } \\
\text { service }\end{array}$} & \multirow{2}{*}{$\begin{array}{l}\text { Personal } \\
\text { authentication }\end{array}$} & $\begin{array}{l}\text { Open/Close through } \\
\text { authentication } \\
\text { (electronic door locks) }\end{array}$ \\
\hline & & $\begin{array}{l}\text { User authentication for } \\
\text { electronic products } \\
\text { including notebooks ant } \\
\text { others. }\end{array}$ \\
\hline & Access control & $\begin{array}{l}\text { Controlling of building } \\
\text { facilities \& vehicle } \\
\text { functions remotely }\end{array}$ \\
\hline \multirow{9}{*}{$\begin{array}{l}\text { Application } \\
\text { service for } \\
\text { information } \\
\text { provision \& } \\
\text { customized } \\
\text { advertisements }\end{array}$} & Tour guide & $\begin{array}{l}\text { Provision of tourist \& } \\
\text { location info. (voice/texts) }\end{array}$ \\
\hline & $\begin{array}{l}\text { Medical } \\
\text { service }\end{array}$ & $\begin{array}{l}\text { Management of medical } \\
\text { records }\end{array}$ \\
\hline & Parking & Check parking spots \\
\hline & \multirow{2}{*}{ Reservation } & $\begin{array}{l}\text { Ticketing by contacting } \\
\text { the posters }\end{array}$ \\
\hline & & $\begin{array}{l}\text { Ticketing for public } \\
\text { transportations }\end{array}$ \\
\hline & $\begin{array}{l}\text { Advertisement/ } \\
\text { Coupons }\end{array}$ & $\begin{array}{lcr}\begin{array}{l}\text { Supply } \\
\text { conduct }\end{array} & \begin{array}{c}\text { coupons } \\
\text { (locations }\end{array} & \text { or } \\
\text { etc.) } & & \\
\end{array}$ \\
\hline & Product info & $\begin{array}{l}\text { Browse product info., } \\
\text { authentication, trace } \\
\text { history, provision of } \\
\text { manuals and A/S info. }\end{array}$ \\
\hline & $\begin{array}{l}\text { Contents } \\
\text { purchase }\end{array}$ & $\begin{array}{l}\text { Download online contents } \\
\text { (e-Books or musics, etc.) }\end{array}$ \\
\hline & Social network & $\begin{array}{l}\text { Immediately transmit the } \\
\text { information read from the } \\
\text { tag to social network(s) }\end{array}$ \\
\hline
\end{tabular}


In order to identify multiple tags in a dense reader environment, a technology which can efficiently control the interference between tags, or between reader and tags should be developed as well as a communication protocol which allows multiple readers to operate simultaneously. An efficient multi-tag identification algorithm has been developed for this reason. [21]-[25].

The most significant benefit of the NFC technology is the fact that most of the current smart phones have the NFC function built in already so that various forms of services are being created and offered. Table 1 shows some of the services being offered.

\section{PROBLEMS OF SHOPPING MALLS AND ANALYSIS}

In most cases, shopping malls have rather complex and crowded sales floors as there are thousands of products on each differently organized sales floor. For this reason, we will try to inform the customers about the location of a certain product with proposed system. Meanwhile, the other problem involves some burdensome services by the sales clerks. There are many customers who would just like to simply browse around. The proposed system will provide the product information only when the customers need them.

The users of this system will be those who are active mainly inside of the shopping mall.

Manager: Shopping mall mangers - take inventory and be in charge of pricing.

Customer: Those who actually purchase products. Buy product and demand product information.

Seller: Those who actually sell the products at the mall. Provide price information or calculate the prices.

Therefore, the diagram of use cases proposed in this study is shown in Fig. 2 and the entire system structure is represented in Fig. 3.

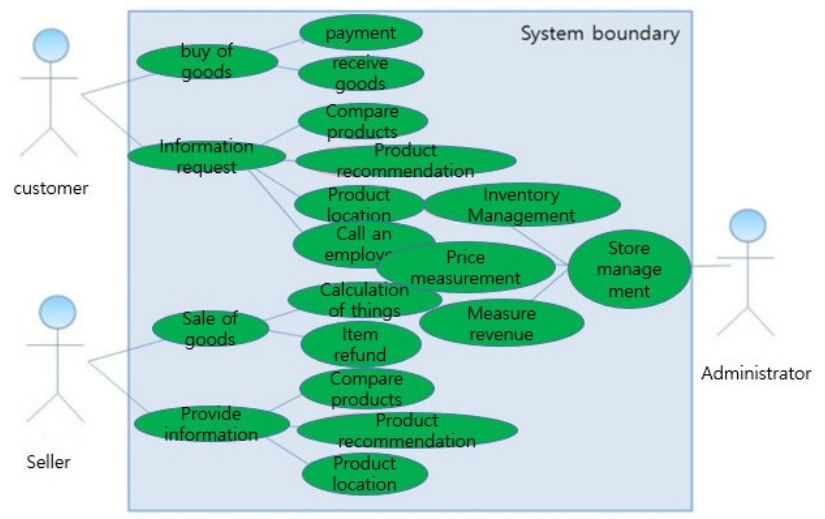

Fig. 2. A Diagram of Use Cases.

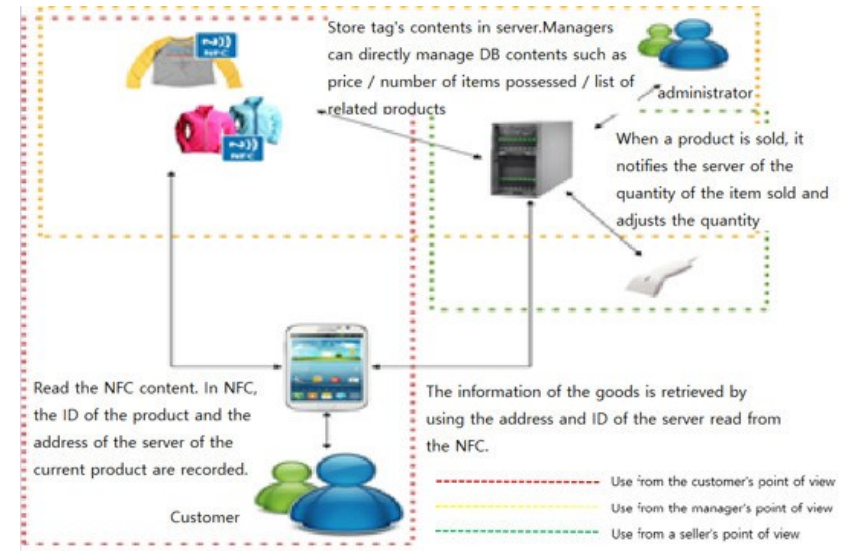

Fig. 3. An Entire Structure Map.

\section{DESIGN OF THE PLATFORM TECHNOLOGY FOR THE SMART SHOPPING MALL USING NFC}

Figure 4 shows the Server-Client structure. The servers on each floor need to communicate each other to find the products not currently displayed or stocked on their respective floors so that they solve the problem by establishing a P2P-type server network.

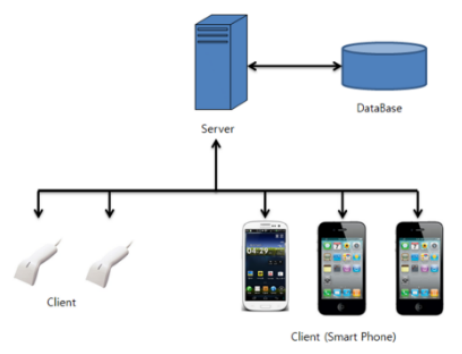

Fig. 4. A Server-Client Structure.

In this network, all the involved servers equally assume the role of both the Server and the Client in Fig. 5. Each server delivers a product information request to all the nodes located on the P2P network and the respective servers respond to the request by sending a reply to the node that has made the request. Since central server is not required for this system, unnecessary waste of resources can be reduced.

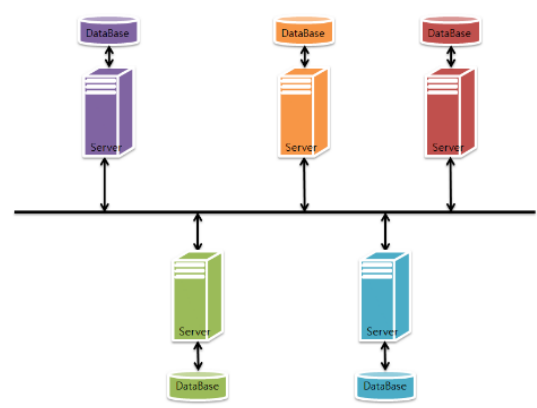

Fig. 5. The P2P Structure between Servers. 
Fig. 6 shows the design of the server proposed in this study. Class Main ( ), Class Server ( ), Class Client (socket) and Class Admin ( ) will be implemented here. Also, Fig. 7 shows a Design of Smart Phone (Client).

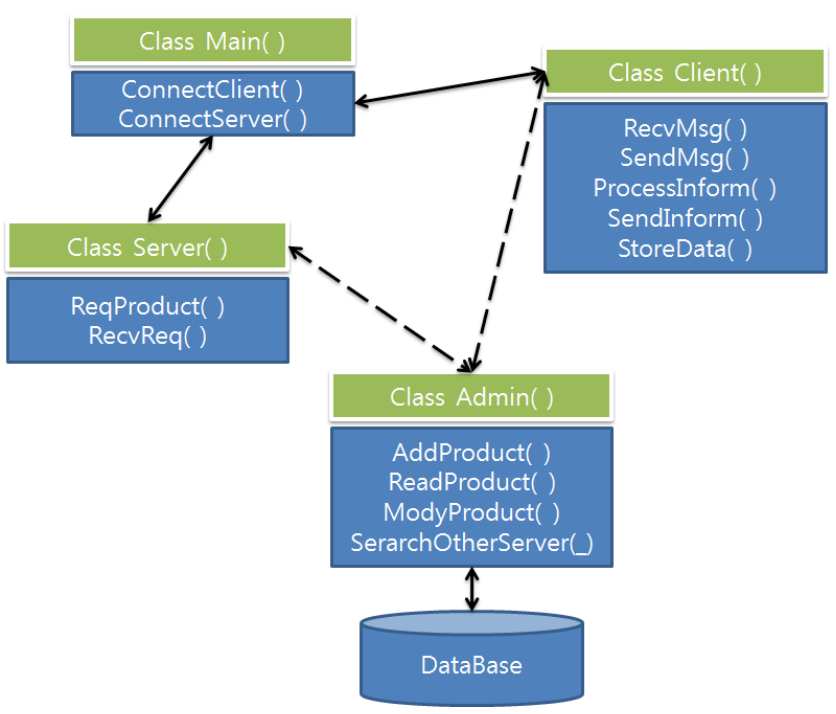

Fig. 6. A Design of Smart Shopping Mall Server.

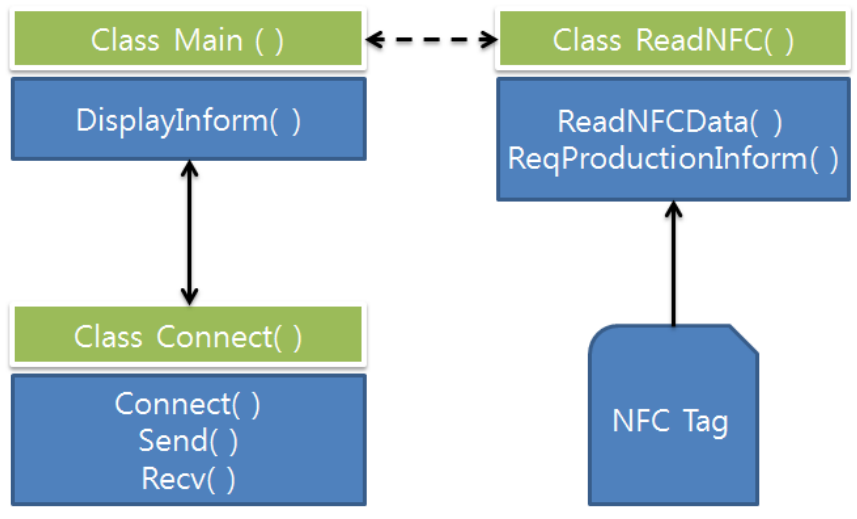

Fig. 7. A Design of Smart Phone (Client).

The design of a computation device that uses the NFC reader dissimilar to the popular bar-code type devices is shown in Fig. 8 Class Connect( ), Class ReadNFC( ), and Class Main( ) will be implemented here.

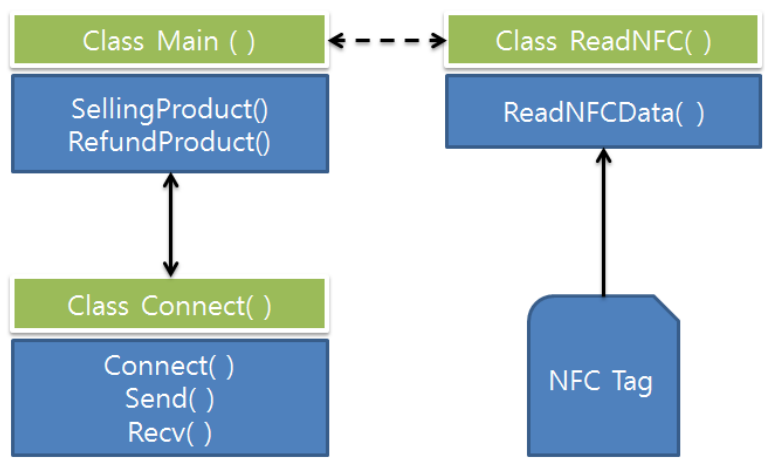

Fig. 8. A Design of Sales/Calculation Device.

\section{CONCLUSION AND FUTURE WORK}

This study introduces a server system developed exclusively for the smart shopping mall or smart stores. Basically, the system has a server-client structure and its primary functions are to categorize or promote/advertise the products efficiently and provide necessary information to the customers in real time while they are enjoying shopping. The system's NFC function allows the reader to read the contents of the NFC tags attached to each product to provide relevant information related to it. Such a system offers a more comfortable shopping experience for the customers who prefer a self-oriented shopping practice in a convenient environment, which is considered as the current or future trend in off-line shopping. Both Android and iOS can be adopted for the system as an OS whereas Java and Object-C are preferable for them, respectively, for the reason that these OS's and languages are still most suitable for system development due to their flexibility and compatibility, as well as their popularity. However, as it was considered that the former (Android with Java) was better for the system to be built in terms of costs and test environment, an Android-based application will be developed first and then an iOS-based one next. Both will be published after obtaining copyright.

\section{REFERENCES}

[1] J-H Huh et al, "A Design of the Platform Technology for the Smart Shopping Mall Using NFC," in 2016 KMMS Fall Conference, Vol. 19, No. 2, pp. 1-3, 2016.

[2] Ying Yuan, Jun-Ho Huh, "A Case Study Analysis of Clothing Shopping Mall for Customer Design Participation Service and Development of Customer Editing User Interface," Mobile Information Systems, pp.1-19, 2018.

[3] P. Volino, F. Cordier, and N. M. Thalmann, "From early virtual garment simulation to interactive fashion design," Computer-Aided Design, Vol. 37, No. 6, pp. 593-608, 2004.

[4] T. J. Kang and S. M. Kim, "Development of threedimensional apparel CAD system: Part II: prediction of garment drape shape," International Journal of Clothing Science and Technology, Vol. 12, No. 1, pp. 26-38, 2000.

[5] N. Metaaphanon and P. Kanongchaiyos, "Real-time cloth simulation for garment CAD," in Proceedings of the 3rd International Conference on Computer Graphics and Interactive Techniques in Australasia and South East Asia, Dunedin, New Zealand, pp. 83- 


\section{$89,2005$.}

[6] F. Han, G.K. Stylios, "3D modelling, simulation and visualisation techniques for drape textiles and garments," in Modelling and Predicting Textile Behaviour, X. Chen, Ed., Vol. 94, pp. 388-421, Woodhead Publishing Ltd, UK, 2009.

[7] D. Terozopoulos, J. Platt, A. Barr, and K. Fleischer, "Elastically deformable models," ACM SIGGRAPH Computer Graphics, Vol. 21, No. 4, pp. 205-214, 1987.

[8] P. Volino and N. Magnenat-+almann, "Versatile and efficient techniques for simulating cloth and other deformable objects," in Proceedings of Annual Conference Series on Computer Graphics, SIGGRAPH, pp. 137-144, Los Angeles, CA, USA, August 1995.

[9] K. Y. Sze and X. H. Liu, "Fabric drape simulation by solid-shell finite element method," Finite Elements in Analysis and Design, Vol. 43, No. 11-12, pp. 819-838, 2007.

[10] J. W. Eischen, S. Deng, and T. G. Clapp, "Finite element modeling and control of flexible fabric parts," IEEE Computer Graphics and Applications, Vol.16, No. 5, pp. 71-80, 1996.

[11] L. Li and V. Volkov, "Cloth animation with adaptively refined meshes," in Proceedings of the Twenty-Eighth Australasian Conference on Computer Science, pp. 107-113, Newcastle, NSW, Australia, January 2005.

[12] D. H. House and D. E. Breen, Cloth Modeling and Animation, A K Peters Ltd., Natik, MA, USA, 2000.

[13] Y Yuan, J-H Huh, "Customized CAD Modeling and design of production process for one-person oneclothing mass production system," Electronics, Vol.7, No.11, pp.1-23, 2018.

[14] S-K Kim, J-H Huh, "A Study on the RFID and 2D Barcode, and NFC and Performance Improvement," in Advanced Multimedia and Ubiquitous Engineering, LNEE, Springer, pp. 773-779, 2018.

[15] J-H Huh, "PLC-based design of monitoring system for ICT-integrated vertical fish farm," Human-centric Computing and Information Sciences, Springer, Vol.7, No.1, pp.1-19, 2017.

[16] B, Magdalena et al, "Please touch the exhibits!: using NFC-based interaction for exploring a museum," in Proceedings of the 11th International Conference on Human-Computer Interaction with Mobile Devices and Services. ACM, 2009.

[16] J-H Huh, "Big data analysis for personalized health activities: Machine learning processing for automatic keyword extraction approach," Symmetry, MDPI, Vol.10, No.4, pp.1-30, 2018.

[17] Darianian, M., and Michael, M. P., "Smart home mobile RFID-based Internet-of-Things systems and services," in 2008 International conference on advanced computer theory and engineering, IEEE, pp. 116-120, 2008.

[18] J-H Huh, T-J Kim, "A location-based mobile health care facility search system for senior citizens," The Journal of Supercomputing, Springer, pp.1-18, 2018.

[19] H.C.V Ngu, J-H Huh, "B+-tree construction on massive data with Hadoop," Cluster Computing, Springer, pp.1-11, 2017.

[20] J-H Huh, "Design and android application for monitoring system using PLC for ICT-Integrated Fish Farm," in Advanced Multimedia and Ubiquitous Engineering, Springer, LNEE, pp. 617-625, 2016.

[21] N, Rajalakshmi et al, "Dhwani: secure peer-to-peer acoustic NFC," ACM SIGCOMM Computer Communication Review, Vol. 43, No. 4, ACM, 2013.

[22] S. Eom, and J.H. Huh, "Group signature with restrictive linkability: minimizing privacy exposure in ubiquitous environment," Journal of Ambient Intelligence and Humanized Computing, Springer, 1-11, 2018.

[23] Kahl, G., Spassova, L., Schöning, J., Gehring, S and Krüger, A., "IRL SmartCart-a user-adaptive contextaware interface for shopping assistance," in Proceedings of the 16th international conference on Intelligent user interfaces, ACM, pp. 359-362, 2011.

[24] J-H Huh, "Server operation and virtualization to save energy and cost in future sustainable computing," Sustainability, MDPI, Vol.10, No.6, pp.1-20, 2018.

[25] Gaeta, M., Loia, V., Orciuoli, F., and Parmentola, M., "A genetic approach to plan shopping in the ami-based blended commerce," n 2013 IEEE International Symposium on Industrial Electronics, pp. 1-6, 2013. 
A Design of the Platform Technology for the Smart Shopping Mall Using NFC: A Software Engineering Approach 